\title{
On the role of the South Pacific subtropical high at the onset of El Niño events
}

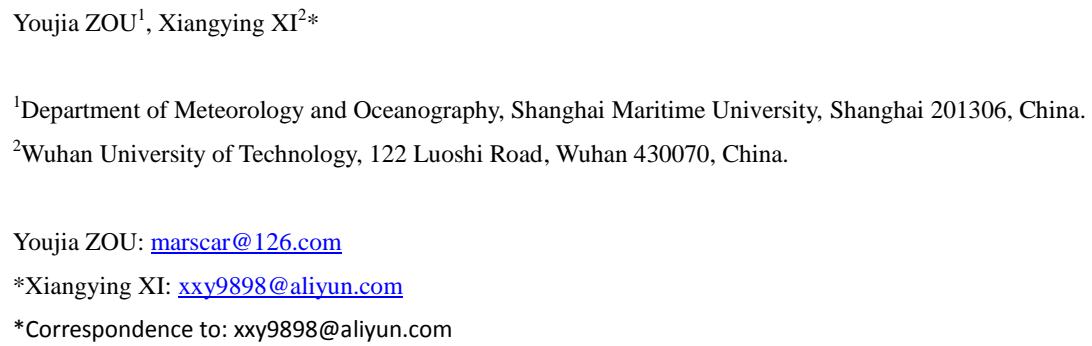

Abstract

Previous studies have suggested that an eastward propagation of the warm pool in the western Pacific during El Niño events may be induced by a weakening of the easterly Trade Winds (Alexander et al. 2002; Bjerknes 1969). However, the dynamic mechanism of the Trade Winds weakening is not well understood. Here we use a model and other published proxy records to demonstrate that the anomalous southward shift of the south Pacific subtropical high (SPSH) may play a crucial role at the onset of El Niño events. By analyzing the relationship between the Trade Winds, the Equatorial Currents, the Eastern Boundary Currents and the SPSH, we find that an anomalous southward shift of the SPSH can result in a weakening of the SE Trade Winds and a southward intrusion of the NE Trade Winds, leading to a southward migration of the Trade Wind-induced Equatorial Currents, including the Equatorial Countercurrent (from $\sim 5^{\circ}-8^{\circ} \mathrm{N}$ to $\sim 0^{\circ}$ ). The warm pool in the western equatorial Pacific is 

Pacific. Moreover, the equatorward upwelling in the eastern South Pacific, usually recurving along the equator, shifts southward along with the SPSH, in turn diverts towards the west at $\sim 15^{\circ} \mathrm{S}$ to feed the westward South Equatorial Currents, resulting in a failure of cooling sea surface in the eastern tropical Pacific, thus a flattening of the thermocline. The model experiments indicate that

the meridional position and intensity of the Equatorial Countercurrent in the Pacific are some of the determining factors in giving rise to El Niño diversity, suggesting that there should be more frequent warm events due to a meridional expansion of the warm pool under global warming.

\section{Key Words}

El Nino; subtropical high; southward shift; weakening of the trade winds; southward shift of the equatorial currents; southward shift of the upwelling;

\section{Introduction}

The El Niño phenomenon, characterized by anomalous Trade Winds and sea surface temperatures (SSTs) in the tropical Pacific (Bjerknes 1969; Ramesh \& Murtugudde 2013), is considered to have global implications with costly consequences. Presently there is a general agreement in the fields of the atmospheric and oceanic science that the warm pool (SSTs greater than about $29^{\circ} \mathrm{C}$ ) in the western Pacific propagating 

1969; Wyrtki 1975; Oldenborgh 2000), there is no scientific consensus on how the Trade Winds slacken or even reverse. The apparent absence of a super warm phase in 2014 that was expected by many models implies that we may still not understand some fundamental aspects of the system. Over the past decades, investigations into the tropical Pacific's role at the onset of El Niño events mainly focused on the SST anomalies (that is, deviations from climatological norms) (Rasmussen \& Carpenter 1982), recharge/discharge of equatorial upper-ocean heat content (Meinen \& McPhaden 2000) and westerly wind bursts (Lengaigne 2004; Fedorov et al. 2014). Recently, the westward equatorial currents were found to be enhanced during La Niña but distinctly reversed during extreme El Niño events (Santoso et al. 2013). Our investigations show that all the above are likely to be directly associated with the South Pacific Subtropical High system (hereafter referred to as SPSH), which has potential (because the Trade Winds, the Westerlies and the Eastern Boundary Currents are all mainly associated with the SPSH and further develop with it in position and intensity) to dominate climate change in South Pacific region by creating

67 significant impacts on the Trade Winds, precipitation patterns and ocean circulations SPSH at the onset of El Niño events. 
Atmos. Chem. Phys. Discuss., https://doi.org/10.5194/acp-2018-82

Manuscript under review for journal Atmos. Chem. Phys.

71 Each year, the South Pacific experiences a seasonal cycle with a northward/southward

72 shift of the subtropical high $(\mathrm{SH})$ in austral winter/summer from $\sim 16^{\circ} \mathrm{S}$ to $\sim 35^{\circ} \mathrm{S}$

73 (Reid et al. 1958). It is generally accepted that the seasonal migrations of the SPSH cannot make significant impacts on the Trade Winds, the Equatorial Currents and the sensitive to the external forcings (Reid et al. 1958).
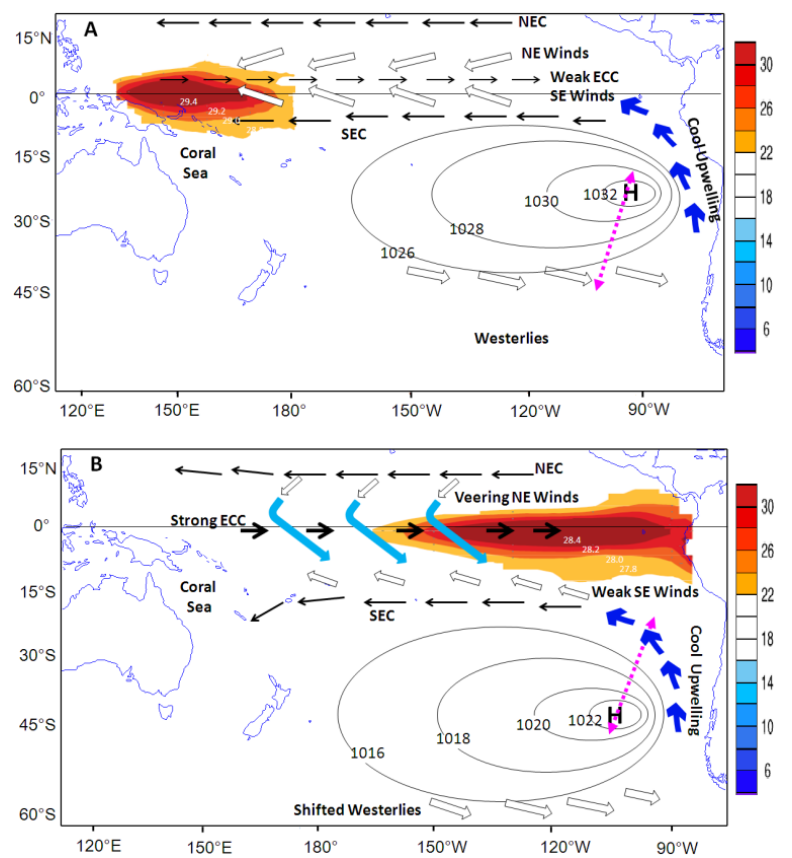

Fig 1.Comparison between normal and El Niño conditions. A, normal condition with strong trade winds, weak ECC and intense upwelling recurving along the equator. Warm waters brought by the weak ECC mix with the strong upwelling in the central equatorial Pacific. B, El Niño condition with a southward shifted SPSH (along with the SE trade winds, equatorial currents and westerlies), veered NE trade winds, strong ECC and weak upwelling deflecting to the west at $\sim 15^{\circ} \mathrm{S}$. Warmer waters brought by the strong ECC mix with the weak upwelling in the eastern South Pacific, leading to SSTs 
anomalies. The dashed arrows in pink color denote the approximate trajectory of the SPSH shift. The solid light blue arrows denote veering Trade Winds. The hollow arrows, solid black arrows and solid dark blue arrows represent the climatological winds, currents and cool upwelling, respectively. The Trade Winds are symmetric about the wind equator (about $\sim 5^{\circ} \mathrm{N}-8^{\circ} \mathrm{N}$ ) in normal condition, rather than the geographic equator.

An anomalous southward migration of the SPSH can result in a weakening of the SE Trade Winds and an enhancement of the Equatorial Countercurrent (ECC), concurrently allowing for a southward incursion of the NE Trade Winds (Fig.1b). As the Trade Wind system shifts southerly, so do the Trade Wind-induced equatorial currents. The Pacific ECC (hereafter referred to as ECC), the strongest (more than 20 Sv) compared with its counterparts (Yu et al. 2000), residing between the North Equatorial Current (NEC) and the South Equatorial Current (SEC), with its mean axis usually around $5^{\circ} \mathrm{N}$ in winter and $8^{\circ} \mathrm{N}$ in summer $(\mathrm{Yu}$ et al. 2000; Tomczak \& Godfrey 2003), migrates to about $0^{\circ}$ or more south in response to the southward shifts of the Trade Wind system, advecting the giant pool of the warm waters eastward along the equator (Fig.1b). In essence, Wyrtki postulated in 1973 that an unusually strong ECC in the western Pacific would lead to an anomalous accumulation of the warm water in the eastern equatorial Pacific and, thus, El Niño event (Wyrtki 1973), but his suggestion has long been overlooked due to lack of plausible mechanisms and a failure of explaining why the warm pool propagates along the equator rather than along the $\sim 5^{\circ} \mathrm{N}$ or $\sim 8^{\circ} \mathrm{N}$ of latitude.

In addition, a southward migration of the NE Trade Winds can result in a veering of the NE Trade Winds from northeast to northwesterly or westerly under the influence 
Atmos. Chem. Phys. Discuss., https://doi.org/10.5194/acp-2018-82

113 of the Coriolis force after the NE Trade Winds cross the equator, further amplifying

114 the intensifying of the ECC (Fig.1b). Meanwhile, a relaxation of the SEC in response

115 to a weakening of the easterly winds is liable to lead to less build-up of heat content in the western tropical Pacific but more heat is retained in the central and the eastern tropical Pacific (McPhaden 1999). The net result of all the above is a reversal of the Walker Circulation, creating westerly winds in the western tropical Pacific and intensifying the eastward ECC, thus establishing a positive feedback. It is noteworthy that the source of the ECC has changed from the warm water to warmer water with southward shifts of its main axis from $\sim 5^{\circ} \mathrm{N}-8^{\circ} \mathrm{N}$ to $\sim 0^{\circ}$, fueling the reversal of the Walker Circulation and the warming in the central and the eastern equatorial Pacific. Moreover, the upwelling in the eastern South Pacific, which usually recurves along the equator, shifts southward along with the Trade Winds/SPSH, in turn diverts towards the west at $\sim 15^{\circ} \mathrm{S}$ during El Niño events to feed the westward SEC

(Figs.1a-b), resulting in a failure of cooling sea surface in the eastern tropical Pacific, thus a flattening of the thermocline.

\section{Simulating El Niño events}

To test whether the SPSH acts as a possible trigger at the onset of El Niño events, we carry out simulation experiments in which we examine the response of SSTs in the tropical Pacific to the observed location and intensity of the SPSH added to a comprehensive climate GCM, HadOPA, which couples the OPA (ocean model) and 
Atmos. Chem. Phys. Discuss., https://doi.org/10.5194/acp-2018-82

Manuscript under review for journal Atmos. Chem. Phys.

Discussion started: 2 May 2018

(c) Author(s) 2018. CC BY 4.0 License.

(c) (i)

135 (For details of the model description, see Methods). We slightly modify this model and assume that the surface wind stress anomaly and the ECC anomaly are a function of the position and strength of the SPSH (see Methods). When the surface wind stress and the meridional position of the ECC vary by artificially tuning the position and strength of the SPSH as a perturbation, the interannual oscillations with SST anomalies retain little change at the initial stage due to its nonlinear effects but start to surge and become highly irregular as the SPSH continuously moves southward in early spring with a gradual weakening. When further perturbation is imposed in late spring, the model produces a broad continuum of El Niño events subsequently in position ranging from the dateline to the eastern tropical Pacific (Extended Data Figs.3a-c). A strong El Niño event occurs in winter in the eastern tropical Pacific as an intense southward shift of the SPSH superimposed on the seasonal cycle takes place (Extended Data Fig.3c and Methods). However, a relative weak El Niño event appears in summer around the dateline when a weak southward migration of the SPSH occurs (Extended Data Fig.3a and Methods). We run this model by changing the meridional position anomalies of the $\operatorname{SPSH}\left(\Delta \varphi_{\mathrm{spsh}}\right)$ to $\sim+10^{\circ}$ and $\sim+12^{\circ}$ of latitude (observed location anomalies), respectively, with a gradual weakening, to simulate the El Niño episodes in 1982 and 1997. As expected, the warm events

153 quickly develop into extreme EP El Niño events with SST anomalies in Niño3

154 exceeding $3.8^{\circ} \mathrm{C}$ and $4.2^{\circ} \mathrm{C}$, respectively, consistent with the observations (Figs.2a-b).

155 (data available online at http://www.cpc.noaa.gov/data/indices) 
Atmos. Chem. Phys. Discuss., https://doi.org/10.5194/acp-2018-82

Manuscript under review for journal Atmos. Chem. Phys.

Discussion started: 2 May 2018

(c) Author(s) 2018. CC BY 4.0 License.

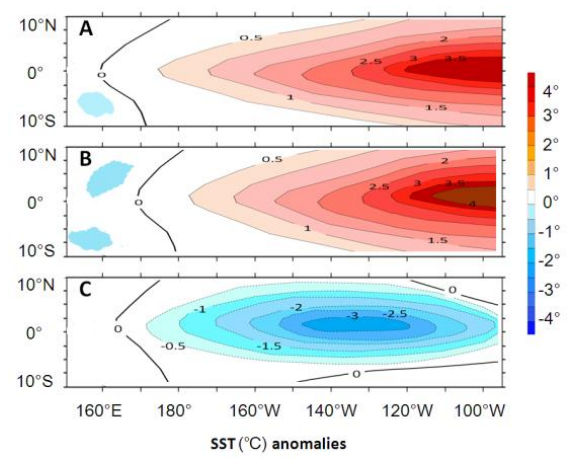

Fig 2.Simulated El Niño and La Nina. A, a strong El Niño in the eastern tropical Pacific as the $\Delta \varphi_{\text {spsh }}$ is $\sim+10^{\circ}$ of latitude. $\mathbf{B}$, a stronger El Niño in the eastern tropical Pacific as the $\Delta \varphi_{\text {spsh }}$ is $\sim+12^{\circ}$ of latitude. C, a La Niña near the eastern tropical Pacific as the $\Delta \varphi_{\text {spsh }}$ is $\sim-4^{\circ}$ of latitude with zonal position anomalies $\left(\Delta \lambda_{\text {spsh }}\right) \sim+7^{\circ}$ of longitude (an eastward anomaly is positive).

\section{Simulating La Niña} by moving the SPSH northerly. The simulation experiments indicate that the warm phase in the eastern tropical Pacific subsequently evolves into a cold phase in late summer the next year as the $\Delta \varphi_{\text {spsh }}$ is about $\sim 4^{\circ}$ of latitude (a northward anomaly is negative) and the zonal position anomalies $\left(\Delta \lambda_{\text {spsh }}\right)$ are $+7^{\circ}$ of longitude (an eastward anomaly is positive), with $2^{\circ} \mathrm{C}-3^{\circ} \mathrm{C}$ cooling of SST anomalies in Niño3 region (Fig.2c), reasonably consistent with the observed records. Northward shifts of the SPSH can enhance the SE Trade Winds and the SEC, weaken the ECC and push the SEC and ECC northwards, leading to a westward shift of the warm pool and the atmospheric convection in the equatorial Pacific. Whether an El Niño event is followed by a La Niña principally rests with the $\Delta \varphi_{\text {spsh }}$ and the upwelling feedbacks which are mainly determined by the southerly onshore winds in the eastern part of the 
Atmos. Chem. Phys. Discuss., https://doi.org/10.5194/acp-2018-82

zonal pressure gradients in the eastern part of the SPSH are steeper (more dense

177 isolines) and the center position of the SPSH from South American coast is more according to the theory of fluid mechanics and Bernoulli's theorem, generating more intense upwelling (the shifting trajectory of the SPSH centre and coast line produce a duct-like passage for the southerly onshore winds with a narrow opening in the north and a relatively wide opening in the south) (Fig.1b). In addition, a more northerly location of the SPSH tends to bring the upwelling to the right position (around equator) in the eastern equatorial Pacific, favoring a La Niña. However, in realistic regimes, the transit from a warm phase to a cold phase may be slightly different from that created by our theoretical models, possibly involving a more complex process, such as an oscillating, a pause or a prolonged evolution, etc.

190

\section{Simulating ECC anomalies}

The experiment in simulating the response of the meridional position anomalies of the ECC $\left(\Delta \varphi_{\mathrm{ecc}}\right)$ to the $\Delta \varphi_{\mathrm{spsh}}$ indicates that the $\Delta \varphi_{\mathrm{ecc}}$ nonlinearly corresponds to the $\Delta \varphi_{\mathrm{spsh}}$ (Figs.3a-d, extended data Fig.5), suggesting that the meridional position and intensity of the ECC are some of the determining factors in giving rise to El Niño diversity. A strong ECC in an appropriate meridional position (around the equator) tends to advect more warm waters to the eastern equatorial Pacific and produce an 
Atmos. Chem. Phys. Discuss., https://doi.org/10.5194/acp-2018-82

Manuscript under review for journal Atmos. Chem. Phys.

Discussion started: 2 May 2018

(c) Author(s) 2018. CC BY 4.0 License.

extreme EP El Niño (a more southerly position of the ECC in winter is easier to be

pulled down to the equator, offering a sufficient explanation for extreme El Niño

frequent warm events due to a meridional expansion of the warm pool in the western
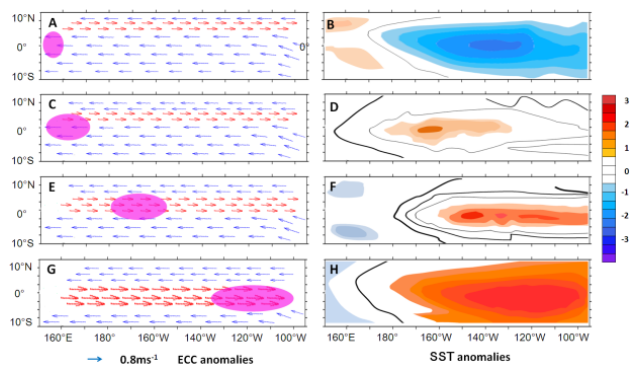

Fig 3.Simulated ECC anomalies and corresponding SST anomalies. A and B, a weak ECC in La Nina condition and corresponding SST anomalies. $\mathbf{C}$ and $\mathbf{D}$, a moderate and southward shifted ECC as the $\Delta \varphi_{\text {spsh }}$ is $\sim+7^{\circ}$ of latitude and corresponding SST anomalies. $\mathbf{E}$ and $\mathbf{F}$, a strong, broad and southward shifted ECC as the $\Delta \varphi_{\mathrm{spsh}}$ is $\sim+10^{\circ}$ of latitude and corresponding SST anomalies. $\mathbf{G}$ and $\mathbf{H}$, a stronger, broader and southward shifted ECC as the $\Delta \varphi_{\text {spsh }}$ is $\sim+11^{\circ}$ of latitude and corresponding SST anomalies. The warm pool is brought to the central or eastern equatorial Pacific by the southward shifted ECC. The red and blue arrows represent the ECC and the NEC/SEC, respectively. The shading area denotes the warm pool on the left panels.

\section{Discussion}

A key question being debated for long time is whether the southward migration of the SPSH is a passive response to El Niño events or is a driver to El Niños. Traditionally, the southward migrations of the SPSH are thought by some authors to be a result of El Niños (McPhaden, 1999; Meinen \& McPhaden 2000; Oldenborgh 2000). In contrast, our investigation reveals that a southward shift of the SPSH is not a passive response 
222 the eastward SSTs anomalies (the equatorward displacements of the NPSH were southward migration of the SPSH were the result of El Niño events. Besides, the SPSH is a large-scale permanent pressure system produced by the global general circulation of the atmosphere, rather than by an individual equatorial low pressure belt in the equatorial Pacific. Therefore the SPSH is not likely to be driven by a regional system, such as the local warming/cooling in the equatorial Pacific. Furthermore, the anomalous migrations of the SH have also been identified in other oceans (Zou et al.

$2312017)$.

The strong support for the southward shifts of the SPSH not being forced by the eastward warm pool during El Niño events comes from two independent investigations into proxy records and experiments throughout the Holocene. The fluctuations of the iron concentrations, which are thought to reflect the precipitation patterns in southern Chile, intimately linking with the westerlies (Lamy et al. 2001), are qualitatively consistent with the periods of ENSO (Moy et al. 2002) in the past 8 kyr (Extended Data Fig.4), suggesting southward displacements of the westerlies in the South Pacific during El Niño events, thus implying the concurrent shifts of the

241 SPSH (because the westerlies are mainly associated with the SPSH and further develop with it in position and intensity). The solar sensitivity experiments with a 
Atmos. Chem. Phys. Discuss., https://doi.org/10.5194/acp-2018-82

comprehensive global climate model indicate that the southward migrations of the westerlies are in line with the variations of solar forcing (Varma et al. 2001), implying that the southward shifts of the SPSH during El Niño events are likely attributed to solar activity, rather than El Niño itself, and further supporting our hypothesis. Furthermore, the timing of the southward displacements of the westerlies was concurrent with that of the strengthening of the ECC, also suggesting a role of the southward displacements of the SPSH at the onset of El Niño events.

Another theory worth noting is the "westerly wind burst" which is recently suggested to be a possible trigger of El Niño events (Lengaigne et al. 2004; Fedorov et al. 2014; Menkes et al. 2014). These westerly winds are thought to be a manifestation of the Madden-Julian Oscillation (MJO) which originates over the Indian Ocean, with a 30 to 60-day period (Madden \& Julian 1972). However, McPhaden (1999) argued that the episodic westerly wind forcing is not a necessary condition for the development of El Niño events because such forcing can be seen during non-El Niño years, and many coupled ocean-atmosphere models also simulate ENSO-like variability without it (McPhaden \& Yu 1999). Our investigation shows that the observed "westerly winds" are to some extent ascribed to the veered NE Trade Winds after crossing the equator (subsequently becoming northwesterly or westerly winds), constituting the lower limb of the reversed Walker Circulation in the western-central tropical Pacific during El Niño events. In essence, the Trade Winds in the equatorial Pacific, in contrast to that in the equatorial Atlantic, are not symmetric about the geographic equator, but about 
Atmos. Chem. Phys. Discuss., https://doi.org/10.5194/acp-2018-82

the $\sim 5^{\circ} \mathrm{N}-\sim 8^{\circ} \mathrm{N}$ of latitude (climatological mean position, a.k.a "wind equator"). This region $\left(0^{\circ}-\sim 5^{\circ} \mathrm{N}\right.$ in the middle of the Pacific) is actually dominated by the SE Trade northwesterly or westerly (mean extending latitudinally from $\sim 5^{\circ} \mathrm{N}$ to $\sim 10^{\circ} \mathrm{S}$ ) once beyond the "wind equator". This explains why the westerly winds can be seen in north of the geographic equator. Occasionally the maximum northern boundary of the westerly winds can reach $\sim 10^{\circ} \mathrm{N}$ under the influence of effects of the entrainment. The ellipse-shaped structure of the SPSH may account for the westerly winds occurring in the western equatorial Pacific first (gradually towards the central Pacific) as the SPSH migrates southward, consistent with the satellite observations indicating reversed Trade Winds mainly confined in the western and central Pacific during El Niño events (Extended Data Fig.6). The model experiments indicate that although the MJO-related westerly wind forcing is not a sufficient condition for the El Niño onset, it can amplify the veered NE Trade Winds if it occurs on time, reinforcing the reversed Walker Circulation and the ECC and, thus, promoting the El Niño-like states to evolve to El Niño events (Fig.3d). This explains why every warm event during the past 50 years was always preceded by the westerly winds (Eisenman et al. 2005).

285 The superposition of the MJO-related westerly winds onto the veered NE Trade 
Atmos. Chem. Phys. Discuss., https://doi.org/10.5194/acp-2018-82 stronger ECC (Figs.3b-d), consistent with the satellite observations (Fig.4a-d). In contrast to some previous studies (Lengaigne et al. 2004; Fedorov et al. 2014), we argue that the eastward propagation of the warm pool in the western equatorial Pacific is likely to be forced mainly by the enhanced and southward shifted ECC rather than by the episodic westerly winds because those westerly winds were observed to be sporadic and not strong enough (Beaufort Scale 5 or less) even if in the most pronounced event in 1997 according to the satellite observations (Extended Data

Fig.6), but these winds may help the eastward development of the warm pool. The likelihood of the westward equatorial currents (SEC) being totally reversed by the sporadic and weak westerly winds is considered low. The newly-discovered "reversed Equatorial Currents" during extreme El Niño events by Santoso et al. (2013), is most likely to be the southward shifted ECC when combined with other evidence from Wyrtki (1973), Lamy et al.(2001) and Varma et al.(2011). This is also confirmed by the satellite observations with an absence of the ECC in previous latitudes $\left(\sim 5^{\circ} \mathrm{N}-8^{\circ} \mathrm{N}\right)$ and an emergence of a new eastward equatorial current around the equator during El Niño events (Fig.4a-d). The fact that the westward transport of the SEC entering the Coral Sea (in northeast of Australia, Fig.1a-b) increases during El Niño events and

307 decreases during La Niña (Kessler \& Cravatte 2013) is suggestive of the meridional shifts of the SEC (the climatologically strongest SEC meridionally ranging from $\sim 2^{\circ} \mathrm{N}$ 
Atmos. Chem. Phys. Discuss., https://doi.org/10.5194/acp-2018-82

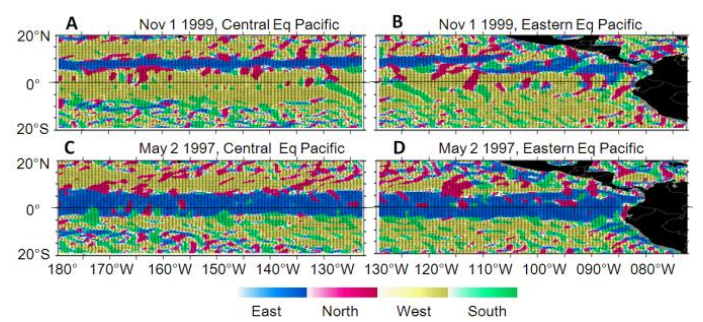

Fig 4. Surface Current derived from satellite observations. $\mathbf{A}$ and $\mathbf{B}$, the positions and directions of the surface currents in the central and eastern equatorial Pacific, respectively, during normal condition (Nov 1, 1999). C and D, the positions and directions of the surface currents in the central and eastern equatorial Pacific, respectively, during El Niño condition (Nov 1, 1997). A broader and southward shifted ECC can be seen around the equator. Different colors denote different directions of the surface

\section{Simulating the tropical wind anomalies and upwelling}

To further examine the response of the tropical wind anomalies to the position anomalies of the SPSH, we run the model by altering the meridional position of the SPSH alone (Methods). Over the tropical Pacific, the model simulation shows that the tropical wind anomalies closely track the variations of the SPSH. As anticipated, the tropical wind anomalies are not evident by changing the zonal position of the SPSH alone (Fig.5). In 1997, the center of the SPSH was observed to shift from $27^{\circ} \mathrm{S}$ in May to $36^{\circ} \mathrm{S}$ in August, to $45^{\circ} \mathrm{S}$ in November, all at about $77^{\circ} \mathrm{W}-80^{\circ} \mathrm{W}$, with zonal wind anomalies at lat $0^{\circ} /$ long $150^{\circ} \mathrm{E}$ from $1 \mathrm{~ms}^{-1}$ in May to $5 \mathrm{~ms}^{-1}$ in August, to $7.5 \mathrm{~ms}^{-1}$ in November, respectively (McPhaden 1999). The superposition of the El Niño-related southward shifts of the SPSH onto the seasonal cycle makes the average 
Atmos. Chem. Phys. Discuss., https://doi.org/10.5194/acp-2018-82

Manuscript under review for journal Atmos. Chem. Phys.

Discussion started: 2 May 2018

(c) Author(s) 2018. CC BY 4.0 License.

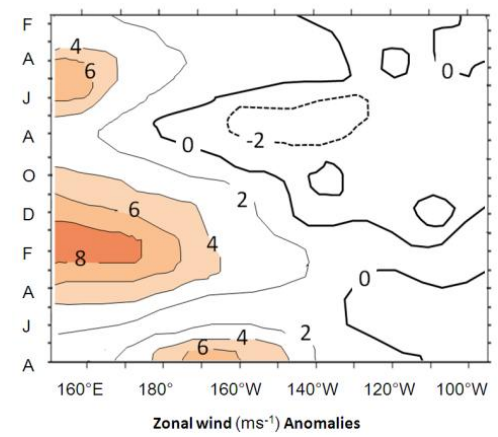

Fig 5.The response of the zonal wind anomalies in the equatorial tropical Pacific to the meridional position anomalies of the SPSH. The zonal wind anomalies (between $5^{\circ} \mathrm{N}$ and $5^{\circ} \mathrm{S}$ ) as the $\Delta \varphi_{\text {spsh }}$ is $\sim+7^{\circ}$ of latitude during Mar-Jun and the zonal wind anomalies as the $\Delta \varphi_{\text {spsh }}$ is $\sim+10^{\circ}$ of latitude during Nov-Apr.

Similar model experiment has been executed for validating the response of the upwelling to the position anomalies of the SPSH, indicating that the upwelling sharply follows the alterations of the SPSH in zonal position, with the meridional position playing a negligible role (Figs.6a-c). The model simulations suggest that the tropical wind anomalies are affected primarily by the meridional position of the SPSH through varying the surface wind stress while the intensity of the upwelling is mainly influenced by the zonal location of the SPSH, with the meridional position and the strength of the SPSH playing a secondary role, consistent with the previous study on the NPSH (Cheshire \& Thurow 2013). The zonal pressure gradients near the center of the SPSH are small but it can be huge with strong southerly onshore winds in the eastern part of the SPSH (the densest isolines, Figs.6b-c), generating intense 
Atmos. Chem. Phys. Discuss., https://doi.org/10.5194/acp-2018-82

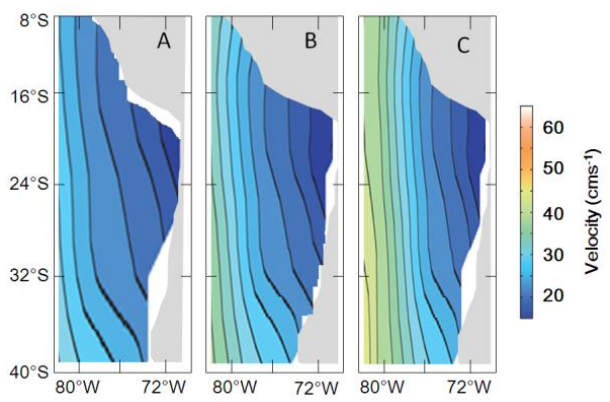

Fig 6.The response of the upwelling feedbacks to the zonal position anomalies of the SPSH. A, the upwelling feedbacks (surface velocity) in normal condition. $\mathbf{B}$, the upwelling feedbacks as the $\Delta \lambda_{\text {spsh }}$ is $+6^{\circ}$ of longitude, $\mathbf{C}$, the upwelling feedbacks as the $\Delta \lambda_{\text {spsh }}$ is $+8^{\circ}$ of longitude (the meridional position and the intensity of the SPSH remain unchanged). The smaller the spacing, the stronger the upwelling feedbacks.

\section{Conclusion}

The model experiments suggest that the SPSH may play a critical role at the onset of El Niño events. Further development of El Niño events (diversity) is likely to be influenced by the subsequent air-sea interactions and the interplay between the eastward warm pool in the western tropical Pacific and the unstable mixing state of warm and cold waters in the central or the eastern tropical Pacific. This does not, however, disparage other drivers which may also play a role at El Niño onset. Understanding the role of the SPSH at the onset of El Niño events is important not only because it is capable of fully reconciling the divergent views of El Niño's origin but also because it exhibits a more plausible explanation of El Niño/La Niña. The apparent lack of real-time forecasting and long-term predictability of El Niño at the current stage implies that we have some way to go in fully understanding the real physical mechanisms of the El Niño/La Niña phenomenon. It is believed that our new 
Atmos. Chem. Phys. Discuss., https://doi.org/10.5194/acp-2018-82

Manuscript under review for journal Atmos. Chem. Phys.

Discussion started: 2 May 2018

(c) Author(s) 2018. CC BY 4.0 License.

(c) (i)

372 findings can better shed light on the role of the SPSH in the genesis of El Niño and

373 may lead to more accurate predictions for a longer period in the future.

375 Acknowledgements authors sincerely acknowledge Trenberth K.E., who is currently

376 working in NCAR, USA, for providing valuable suggestions in the contributors of El

377 Niño onset.

378

Author Contributions Both authors contributed equally to this work.

Zou collected all data, prepared the manuscript and figures, and performed the

381

382

383

384

385

386

387

388

389

84
analysis. Xi was responsible for data collection, laboratory efforts and contributed to the computer programming and the model simulating. Both authors discussed the results and provided inputs to the paper.

\section{References}

Alexander, M. A. et al., 2002: The atmospheric bridge: The influence of ENSO teleconnections on air-sea interaction over the global oceans. J. Clim. 15, $2205-2228$.

Bjerknes, J.A, 1969: Atmospheric teleconnections from the equatorial pacific. Mon. Wea. Rev. 97(3):163-172.

Chen, D.K. et al., 2015: Strong influence of westerly wind bursts on El Niño diversity. Nature Geoscience 8(5). 
Atmos. Chem. Phys. Discuss., https://doi.org/10.5194/acp-2018-82

Manuscript under review for journal Atmos. Chem. Phys.

Discussion started: 2 May 2018

(c) Author(s) 2018. CC BY 4.0 License.

Cheshire, H. \& Thurow, J, 2-13: High-resolution migration history of the Subtropical High/Trade Wind system of the northeastern Pacific during the last $\sim 55000$ years: Implications for glacial atmospheric reorganization, Paleoceanography $\mathbf{2 8 ,}$ 319-333.

Cravatte, S., Delcroix, T., Zhang, D., Mcphaden, M. \& Leloup, J, 2009: Observed freshening and warming of the western pacific warm pool. Clim. Dynam. 33(4), $565-589$.

Eisenman, I., Yu, L. \& Tziperman, E, 2005: Westerly wind bursts: ENSO’s tail rather than the dog. J. Clim. 18, 5224-5238.

Fedorov, A. V., Hu, S., Lengaigne, M. \& Guilyardi, E, 2014: The impact of westerly wind bursts and ocean initial state on the development and diversity of El Niño events. Clim. Dynam. 44, 1381-1401.

Kessler,W.S. \& Cravatte, S, 2013: ENSO and Short-Term Variability of the South Equatorial Current Entering the Coral Sea. J. Phys. Oceanography. 43(5):956-969.

Lengaigne, M. et al., 2004: Triggering of El Niño by westerly wind events in a coupled general circulation model. Clim Dyn. 23(6):601-620.

Lamy, F., Hebbeln, D., Röhl, U. \& Wefer, G, 2001: Holocene rainfall variability in southern Chile: a marine record of latitudinal shifts of the Southern Westerlies. Earth \& Planetary Science Letters 185(s3-4):369-382.

Madden, R. A. \& Julian, P.R, 1972: Description of global-scale circulation cells in the tropics with a 40-50 day period. J.Atmos. Sci. 29, 1109-1123. 
Atmos. Chem. Phys. Discuss., https://doi.org/10.5194/acp-2018-82

Manuscript under review for journal Atmos. Chem. Phys.

Discussion started: 2 May 2018

(c) Author(s) 2018. CC BY 4.0 License.

McPhaden, M. J, 1999: Climate oscillations: Genesis and evolution of the 1997-98 El

Niño. Science 283, 950-954.

McPhaden,M.J. \& Yu, X, 1999: Equatorial waves and the 1997-1998 El Niño.

Meinen, C. S. \& McPhaden, M. J, 2000: Observations of warm water volume changes $3551-3559$.

Menkes, C. E. et al., 2014: About the role of Westerly Wind Events in the possible development of an El Niño in 2014. Geophys. Res. Lett. 41, 6476-6483.

Moy, C. M., Seltzer, G. O., Rodbell, D. T. \& Anderson, D. M, 2002: Variability of El Niño/Southern Oscillation activity at millennial timescales during the Holocene epoch. Nature 420(6912):162-165.

Oldenborgh, G. J. V, 2000: What Caused the Onset of the 1997-98 El Niño? Mon. Wea. Rev. 128, 2601-2607.

Picaut, J., Masia, F. \& Penhoat, Y. D, 1997: An advective-reflective conceptual model for the oscillatory nature of the ENSO. Science 277, 663-66.

Ramesh, N. \& Murtugudde, R, 2013: All flavours of El Niño have similar early subsurface origins. Nature Climate Change 3(1):42-46.

Rasmussen, E. M. \& Carpenter,T. H, 1982: Variations in sea surface temperature and surface wind fields associated with the Southern Oscillation/El Niño. Mon. Weath. Rev. 110, 354-384.

Reid, J. L., Roden, G. I. \& Wyllie, J. G,1958: Studies of the California Current system, 
Atmos. Chem. Phys. Discuss., https://doi.org/10.5194/acp-2018-82

Manuscript under review for journal Atmos. Chem. Phys.

Discussion started: 2 May 2018

(c) Author(s) 2018. CC BY 4.0 License.

Rollenbeck, R. et al., 2015: Climatic Cycles and Gradients of the El Niño Core

Santoso, A. et al., 2013: Late-twentieth-century emergence of the El Nino propagation asymmetry and future projections. Nature 504(7478):126-130.

444

445

Tomczak, M. \& Godfrey, J. S, 2003: Regional Oceanography: An Introduction, 2nd

$$
\text { edition, pp. } 390 .
$$

UK Hydrographic Office. Sailing Directions, NP61 \& 62, 13th edition, pp 32-39,

$$
\text { Taunton, UK (2013). }
$$

Varma, V., Prange, M., Lamy, F., Merkel, U. \& Schulz, M, 2011: Solar-forced shifts of the southern hemisphere westerlies during the holocene. Climate of the Past Discussions 7(2), 339-347.

Wyrtki, K, 1973: Teleconnections in the Equatorial Pacific Ocean. Science 180, 66-68.

Wyrtki, K, 1975: El Niño- the dynamic response of the equatorial Pacific Ocean to atmospheric forcing. J. Phys. Oceanogr. 5, 572-584.

Yu, Z., Mccreary, J. P. J., Kessler, W. S. \& Kelly, K. A, 2000: Influence of Equatorial Dynamics on the Pacific North Equatorial Countercurrent. J. Phys. Oceanography. 30, 3179-3190.

Zou, Y.J, Xi, X.Y \& Zhang, C.Y, 2017: Southward migrations of the Atlantic Equatorial Currents during the Younger Dryas. Limnology and Oceanography. 62, 
Atmos. Chem. Phys. Discuss., https://doi.org/10.5194/acp-2018-82

Manuscript under review for journal Atmos. Chem. Phys.

Discussion started: 2 May 2018

(c) Author(s) 2018. CC BY 4.0 License.

(c) (i)

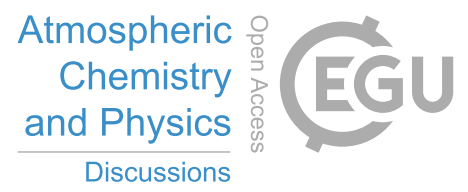

